For citation: Thanh D. V. (2019). Macro-econometric Model for Medium-Term Socio-Economic Development Planning in Vietnam - Part 1: Structure of the Model. Ekonomika Regiona [Economy of Region], 15(1), 121-136 doi 10.17059/2019-1-10

UDC: 338.27

JEL: C51, C53, E17

D. V. Thanh

Nguyen Tat Thanh University (Ho Chi Minh, Vietnam; e-mail: dvthanh@ntt.edu.vn)

\title{
MACRO-ECONOMETRIC MODEL FOR MEDIUM-TERM SOCIO-ECONOMIC DEVELOPMENT PLANNING IN VIETNAM. PART 1: STRUCTURE OF THE MODEL ${ }^{1}$
}

Vietnam builds the market economy from the planned economy, in which development plans, especially the medium-term socio-economic development plans, were determined by the leading economic management tools. Currently, the development plans remain the important tools of economic management. However, the contents and methodologies for development planning have changed considerably. The plans have been built according to the direction of the market and consider macroeconomic forecasts as the most important input for planning. The purpose of this paper is to briefly present the structure of a macro-econometric model for medium-term socio-economic development planning in Vietnam. The model is based on the main ideas of the forecasting procedures and the system of forecast models for strategic planning in the Russian Federation. Furthermore, the model utilizes the experience of macro-econometric models in other countries. This model is based on the approaches of supply and demand, and is organized into blocks that have a close relationship to combine forecasts from the built model and using judgmental methods in a favourable way. The model can fully forecast the needs of socio-economic development planning. It is also used to build forecast scenarios and to assess the impact of shocks and economic policies.

Keywords: econometric models, forecasting models, models and applications, judgmental method, national economic planning, economic plans, forecasting procedures, forecasting scenarios, economic forecasts, economic forecasting

\section{Introduction}

Since 1986, Vietnam has begun the transition from the centrally planned economy to the socialist-oriented market economy and the implementation of economic reforms. Policies that opened up the economy to the rest of the world have been boosted since 1995. Since then, the structure of the economy as well as the development planning methodology of the economy has also changed. The socio-economic development plans (SEDPs) in Vietnam include the socio-economic development strategy, master plan, five-year and annual SEDP, in which the five-year (medium-term) SEDP is the most important. The medium-term SEDP in Vietnam is developed according to the approach of planning of the United Nations for national economic development strategic plan ${ }^{2}$. This medium-term SEDP includes contents to answer the 4 strategic questions as follows: (1) Where are we now? (2) Where can we arrive and where do we

\footnotetext{
${ }^{1}$ (C) Thanh D. V. Text. 2019.

2 UN-HABITAT - United Nations Human Settlements Programme (2005). Promoting Local Economic Development through Strategic Planning - Volume 2, Modules: One, Two, Three, Four. ISBN: 92-1-131721-3, HS735//05E.
}

want to go? (3) How do we get there? (4) Have we arrived?

To answer the question: Where can we go? and, in part, the question: How do we get there? it is necessary to have good forecasts for socio-economic development planning.

The project "Research on medium-term socio-economic forecasting methodologies in the Russian Federation and its applicability to Vietnam" for implementing the tasks of the Protocol between the Governments of Vietnam and the Russian Federation has proposed a comprehensive system of solutions for improving the quality of forecasts for medium-term socio-economic development planning, in which the creation of systematic, legal and detail forecasting procedures and the building of a macro econometric model are important contents implemented in this project [1].

In the process of socio-economic development planning in Vietnam, managers and planners need forecasts of economic growth; inflation and prices; residential income; consumption and saving; investment for development and balance capital for investment; population, employment, labour force, labour demand \& supply and mis- 
match of labour demand \& supply; budget revenue \& expenditure and state budget balance; export, import and trade balance; energy demand \& supply and energy balance.

Until now, the essential forecasts above for medium-term socio-economic development planning are not still complete. They are received from many independent sources using different forecast approaches. Thus, in many cases the forecasts are in conflict and it is very difficult to incorporate them. Moreover, foreign and domestic factors effecting the socio-economic development of Vietnam in the medium-term have not been adequately defined and are not unified for managers, planners and forecasters. That even happens within the Ministry of Planning and Investment. It is the leading organization for planning, organizing the implementation, monitoring and evaluating the implementation of national socio- economic development plans. Therefore, the quality of forecast scenarios for socio-economic development planning is limited. When a foreign and/or domestic factor changes significantly, these scenarios become inappropriate and this can create many difficulties for managing and regulating the economy by the Government.

The macro-econometric model for socio-economic development planning in Vietnam (the Vietnam's Model for short) will overcome the drawbacks mentioned above. This model is based on experiences implementing the forecasting procedures [2] as well as main ideas of the forecasting system for strategic planning in the Russian Federation ${ }^{1}$ [3-7]. It is also improved using macro-econometric models of the Chinese economy [8-10], and especially the China's Macro Economic Annual Model [8]. The methodologies for forecasting the labour demand, energy demand in the Vietnam's model are developed from the experiences of South Korea [11] and New Zealand [7, 12] respectively.

In the context of the transitional economy, the System of National Accounts according to the international statistical standard is applied for first time in Vietnam in 1995, and it is still in the process of improvement. Economic data by year are short, and the data quality for building econometric models for the medium-term socio-economic development planning is also not high. In order to improve the forecast accuracy, in the Vietnam's model all behavioural equations are estimated unbiasedly. To achieve this, dummy

\footnotetext{
${ }^{1}$ Putin, V. (2009). Decree on the order of making forecasts of socio-economic development of Russian Federation, No. 596, July 22, 2009. (in Russ)
}

variables are used to handle unusual fluctuations of data points (in some cases, smoothed data is used to replace those abnormal data points), the residual of every estimated equations is considered as an ARMA model. If necessary, the time variable $T$ is included in the estimated equations as a new explanatory variable to capture information, which cannot be explained by the explanatory variables in these equations. This is very different in comparison with the econometric models cited above.

The Vietnam's model is organized into blocks having close ties with each other. The exogenous variables reflecting the foreign and domestic factors are commonly used for all the blocks. In addition, in this model, many exogenous inputs of a block behind are the endogenous variables of preceding blocks, and few blocks can also have other exogenous variables.

The approach of building the Vietnam's model allows easily combining forecasts from the built model and other statistical models as well as from the built model and using judgmental methods for each block while it still ensures balance and non-contradiction of the forecasts according to economic theories. Today, the combination of forecasts from quantitative models as well as from a quantitative model and using expert judgements is very popular in the socio-economic fields [13, $14,15]$.

The data to build the Vietnam's model are collected from the General Statistics Office (GSO), from specialized ministries of Vietnam and from reputable international agencies.

The structure of this paper is as follows: the section 2 introduces briefly the forecasting procedures for socio-economic development planning and the forecast models that were applied in Vietnam. The section 3 introduces the related works and main contributions of the paper. The section 4 presents the theoretical framework of the Vietnam's model, method of data pre-processing and methodology to test and select a right format of nominated function for behavioural equations. The section 5 presents in an abbreviated form the structure of the built model; the section 6 presents conclusions.

\section{Forecasting Procedures and Models for Development Planning in Vietnam}

\subsection{Forecasting Procedures}

The forecasting procedures for medium-term socio-economic development planning in Vietnam can be presented in a much abbreviated form as follows [1]. 
Step 1: Forecasting the growth rates of the most important socio-economic indicators in the next five years: GDP of the whole economy and 3 industries of primary, secondary and tertiary sectors, Consumer Price Index, investment for development of the whole society, budget revenue, total export and total import, unemployment at national scope. These forecasts are included in the Prime Minister's directive guiding the ministries and provincial authorities in medium-term socio-economic development planning.

Step 2: Based on the forecasts of socio-economic indicators in the Step 1, the ministries and provincial authorities will forecast socio-economic indicators in fields and regions managed by them. From that, the ministries and provincial authorities propose their SEDPs.

Step 3: The Ministry of Planning and Investment synthesizes forecasts implemented by the ministries, provinces and the SEDPs of these organizations, adjusts the previously forecasts and provides new forecasts for socio-economic development planning at national scope and proposes the SEDP of the country.

Step 4: Based on the forecasts as well as the medium-term SEDP at national scope, the ministries and provincial authorities correct their forecasts and SEDPs.

In general, these procedures are quite similar in the Russian Federation. However, in the Russian Federation, the forecasting procedures for strategic planning are more specific, detailed and systematic than in Vietnam, and have been legalized $^{1}[2]$. The implementation of the forecasting procedures aforementioned for medium-term socio-economic development planning in Vietnam has shown the following key limitations:

First, the forecasts in the Prime Minister's Directive did not provide sufficient information for the implementation of forecasting by the ministries and provincial authorities. On the basis of the provided forecasts, these organizations are still facing many difficulties to continue implementing their own forecasts for medium-term socio-economic development planning at the national level as well as at the local level.

Second, foreign and domestic factors affecting the socio-economic development of Vietnam in medium-term (especially foreign factors) have not been concretely and uniformly determined. Usually, the forecasts of foreign factors differ significantly between the ministries and provinces.

\footnotetext{
${ }^{1}$ Putin, V. (2009). Decree on the order of making forecasts of socio-economic development of Russian Federation, No. 596, July 22, 2009. (in Russ)
}

Moreover, forecasts implemented by the ministries and provinces for socio-economic development planning are often in conflict with each other.

Third, incorporating and balancing the forecasts from the ministries and provinces encounters many difficulties, consumes many time and needs many other resources.

Fourth, the methodology for generating forecast scenarios is not clearly defined. The formulation of forecast scenarios for the medium-term socio-economic development plan is complicated. It is very difficult to get the consensus of the stakeholders.

Fifth, the medium-term SEDP at national scope is not flexible for changes of socio-economic situation in the country and abroad. The adjustment of policies to implement the medium-term SEDP as well as the adjustment of planned target indicators is often untimely and difficult to ensure accuracy and rationality.

In the context of these limitations, the forecasting procedures for strategic planning in the Russian Federation $^{2}$ [2] are truly valuable experiences and the Vietnam's model should be in line with the forecasting procedures for medium-term socio-economic development planning.

\subsection{Applied Forecasting Models}

Stakeholders in socio-economic development forecasting and planning at provincial and national scopes in Vietnam are the provincial authorities and ministries. A provincial authority forecasts socio-economic development in the province, while the ministries make predictions for the area of their responsibility. For example, the Ministry of Planning and Investment is responsible for the forecast of Growth and Inflation of the economy, Income, Consumption, Investment for development and Capital Stock; the Ministry of Finance is responsible for budget revenue and expenditure, and the Ministry of Industry and Trade responds for Foreign trade and energy demand supply, total exports and total imports, etc.

The forecast methods for socio-economic development planning used by provincial authorities are mostly manual. These methods are based on the forecasts outlined in the Prime Minister's Directive and on the analysis and adjustment of the average growth rate of socio-economic indicators in the province in the previous five years. The methodologies of forecasting the socio-economic indicators in most ministries are based on the time series analysis methods. Ministries use small-scale

\footnotetext{
${ }^{2}$ Ibid.
} 
macro-econometric models with no relevance with each other. Only the Ministry of Planning and Investment has built rather large scale macro-econometric models aimed at assessing the impact of certain important economic policies of the Government such as impact of Vietnam's accession to the World Trade Organization or impact of tax reform policies, etc. These models are not intended for medium-term socio-economic development planning, so the forecasted issues for socio-economic development planning of this ministry are not comprehensive and complete. This shows that in order to improve the quality of the medium-term SEDP in Vietnam, firstly, it is necessary to build macro econometric models for development planning.

\subsection{Requirements for the Proposed Forecasting Model}

The proposed model should improve the implementation of the forecasting procedures for medium-term socio-economic development planning in Vietnam and overcome the above shortcomings. Namely, it has to allow implementing the forecasts in 9 areas:

(i) economic growth at constant and current prices for the whole economy, in 3 industries: Agriculture - Forestry - Fisheries (primary), Industry - Construction (secondary), Services (tertiary) and for the 21 economic sectors of level 1 ;

(ii) population, employment, labour force and labour demand by occupations and by levels of training for the 21 economic sectors of level 1;

(iii) the income of urban and rural population;

(iv) residential saving, household consumption as well as government consumption;

(v) the investment for development of the whole society, investment in the economic sectors and investment by the state sector, investment by the private sector, investment by the foreign-invested sector, the capital stock and the fixed capital formation;

(vi)Consumer Price Index, GDP deflator of the whole economy and of the 21 economic sectors of level 1, the Investment Price Index of the whole economy and of 3 industries of primary, secondary and tertiary sectors, the Export Price Index as well as the Import Price Index;

(vii) budget revenues, expenditures and balance of the state budget;

(viii) total exports, total imports and trade balance;

(ix) energy demand - supply and balance of electricity supply and demand.

This model assists the verification of appropriateness, the synthesis and balance of fore- casts implemented by the ministries and provincial authorities. The model allows to create forecast scenarios for socio-economic development planning at national scope in a convenient manner. Moreover, the model allows assessing the impact of certain economic policies and shocks. The model can be used to assist the implementation of the 5-year and annual SEEDs such as to adjust the planned target indicators in a context of changing socio-economic situations, etc.

\section{Related Works and Main Contributions}

\subsection{Related Works}

The Russian Federation has extensive experience in strategic planning. This nation has implemented the law on strategic planning, in which the forecast has been defined as one of the 3 most important contents of strategic planning. The Federation Government also issued the Decree No. 596 on forecasting procedures for strategic planning ${ }^{1}$ [2], where main foreign and domestic factors affecting socio-economic development in the Russian Federation were very clearly defined. These factors are used to define assumptions for establishing forecast scenarios in strategic planning. The forecasting system for the strategic planning in the Russian Federation is very large and complicated [3]. It provided very comprehensive and detail forecasts for strategic planning at both the national and region levels. This system includes 9 quantitative models related closely to each other [3] in which the first 8 models are used for forecasting and the 9th model - the input-output based model is used to balance forecasts $[3,6]$. The forecasting system for the Russian Federation's strategic planning does not include the component for forecasting labour market. This component is held separately. The implementation of forecasts is done sequentially, repeatedly, and forecasts are evaluated and adjusted for each iteration. The main disadvantage of this system mainly lies in that there should be a large system of statistical agencies to collect comprehensive and detailed statistical data; it takes a lot of time and other resources to build such system of forecast models, and it is difficult to evaluate impacts of shocks and of economic policies for the whole economy using all models in the system.

The China's macro-econometric models including the China's Macro Econometric Annual Model [8], the ICSEAD's Econometric Model [9]

\footnotetext{
${ }^{1}$ Putin, V. (2009). Decree on the order of making forecasts of socio-economic development of Russian Federation, No. 596, July 22, 2009. (in Russ)
} 
and the China's economic model for project FAIR [10] are large models. China's Macro Econometric Annual Model is the official macro-econometric model in China. This official model provides forecasts of various economic indicators. It is applied to forecast of China's economic growth during "Ninth-Five Year" and "Tenth-Five Year" and to simulate the influences of different policies to economic growth.

The macro-econometric models of the Chinese economy are supply-oriented. The production functions in each model are slightly different and play important roles. The forecasts of labour supply and demand, supply and demand for certain key products; budget revenue and expenditure are not yet implemented by these models. Moreover, the economic sectors considered in these models are only the primary, secondary and tertiary industries.

Currently, the forecast information about demand-supply of labour and energy (especially, about demand) is very important for socio-economic development planning in Vietnam. Implemented in the framework of Korea's knowledge sharing program for Vietnam, the working paper [11] shows that the current statistical data which are available in Vietnam enables the forecast of labour demand by the occupations of level 1 and by levels of training for the 21 economic sectors of level 1, but does not allow forecasting labour supply. This experience is further developed in the Vietnam's model. The forecasting methodology of energy supply and demand in the Russian Federation [7] is quite similar to that of New Zealand [12]. This methodology is also applied in the Vietnam's model.

\subsection{Main Contributions}

This paper addresses the limitations of the forecasting procedures and of forecasted issues for Socio-economic development planning in Vietnam and proposes a macro-econometric model (called Vietnam's model) to improve the quality of forecasts for medium-term Socioeconomic development planning.

The Vietnam's model was developed based on the ideas of the forecasting procedures and the forecast system for strategic planning in the Russian Federation. It overcomes the disadvantages aforementioned in the forecast system for strategic planning in the Russian Federation as well as some limitations in forecasted issues in the China's macro-econometric models. Namely, the exogenous variables which are foreign factors, the systematic relations between the components of the Vietnam's model as well as the estab- lishment of the conditions for creating the forecasting scenarios were developed from experiences of the Russian Federation ${ }^{1}[2-5,7,16]$. It is different from the forecasting system for strategic planning in the Russian Federation, basically, the forecasting components for medium-term socio-economic development planning in Vietnam were included in one macro econometric model, and therefore the complexity of the forecast system for socio-economic development planning is minimized.

The Vietnam's model is considerably different from the China's macro-econometric models [8-10]. The Vietnam's model is built according to both the approaches of supply and demand. The forecasting components of labour demand, energy demand-supply, state budget revenue and expenditure were integrated in this model. This integration is justified by the following reasons: the labour demand in Vietnam largely depends on the scale of the economy and government policies especially on wage, education policies and on investment for development; the energy demand depends at a great extent on the scale of the secondary and tertiary industries, and price and social security policies of the government. And all these factors are available in the Vietnam's model.

\section{Theoretical Framework, Test and Selection of Models}

\subsection{Theoretical Framework of the Vietnam's Model}

Assuming that the production technology of the Vietnamese economy is constant according to scale, namely that the production functions return to the same scale; the depreciation rates of the whole economy and economic sectors are unchanged and the price of state-owned monopoly products (such as electricity price for different purposes) is determined rigidly, the theoretical framework of the Vietnam's model is shown in the Figure 1 below:

In the Vietnam's model, foreign factors reflect conditions for the development of the Vietnamese economy (such as the world price of basic input materials and of key products of the economy, the Export Price Index of merchandises and services of the world and of major partners, etc.) and reflect foreign demands of the Vietnamese economy (world economic growth, world total trade, import growth of major partners of the economy, FDI into

\footnotetext{
${ }^{1}$ Putin, V. (2009). Decree on the order of making forecasts of socio-economic development of Russian Federation, No. 596, July 22, 2009. (in Russ)
} 


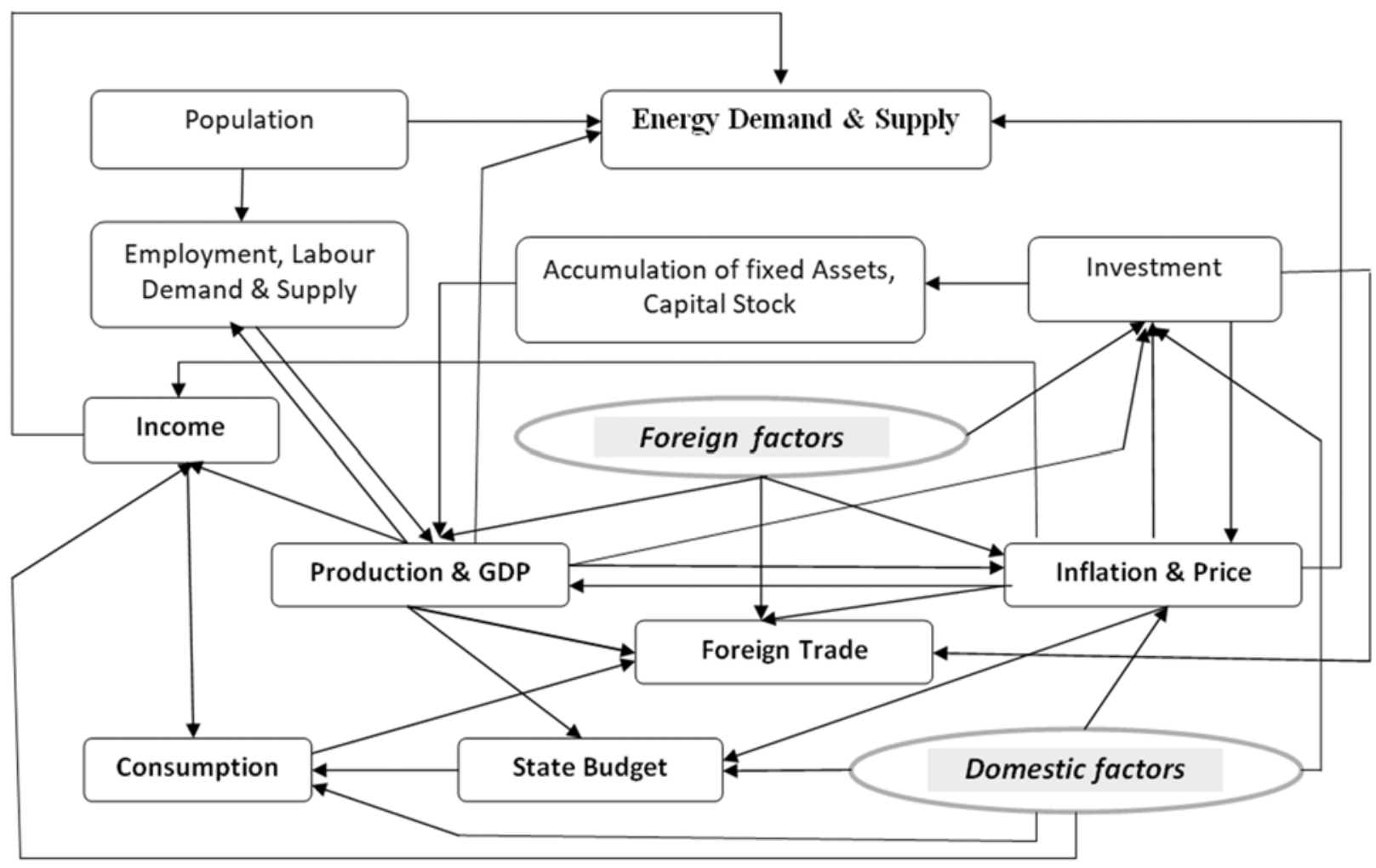

Fig. 1. Theoretical framework of the Vietnam's model

Vietnam, etc.). Domestic factors reflect changes in the Government's economic policies such as in the monetary policies (exchange rate of VND and USD, M2 money supply, interest rate, etc.), in the fiscal policies (expenditure for defence, education, health, national security and social security; energy price for different using purposes, investment policies for development by state budget, etc.) and commitments in bilateral and multilateral agreements (the changes of structure and two-ways trade between Vietnam and its partners). In essence, the foreign factors are determined under the approach in but not quite like in ${ }^{1}[2-4]$.

\subsection{Analysis and Pre-processing of Data}

To build the Vietnam's model, data were collected for the period after 1995 (the year, when the statistical system of Vietnam switches to use the System of National Accounts and Vietnam began to integrate strongly to the world economy). Much of the data were collected from the $\mathrm{GSO}^{2}$. Data on foreign investment were collected from the Ministry of Planning and Investment, data on budget revenues and expenditures were gathered from the Ministry of Finance, currency data

\footnotetext{
${ }^{1}$ Putin, V. (2009). Decree on the order of making forecasts of socio-economic development of Russian Federation, No. 596, July 22, 2009. (in Russ)

${ }^{2}$ GSO - General Statistic Office of Vietnam, https://www.gso. gov.vn/, Accessed January 6, 2018.
}

are sourced from the State Bank. Moreover, there are many other statistical data (including forecasted data of exogenous variables that are the foreign factors) collected from other international agencies, such as $\mathrm{IMF}^{3}$ or the National Institute of Economic and Social Research of the United Kingdom through the use of NiGEM software ${ }^{4}$, etc.

Before building this model, statistical characteristics of important single variables were analysed and synthesized using the EViews ${ }^{5}$ statistical software. Furthermore, this software was used to build the Vietnam's model. The statistical measures such as maximum, minimum, mean, median, standard deviation, Skewness and Kurtosis of variables are automatically calculated using the software. The analysis and synthesis of statistical characteristics of each variable were done through analysing its graph and the aforementioned statistical measures of the variable. From this analysis, basically it was possible to identify a probability distribution and abnormal changes of a variable. In some cases, data pre-processing mainly using the smoothing methods was performed to overcome abnormal data points.

${ }^{3}$ IMF - International Monetary Fund, http://www.imf.org/, Accessed October 15, 2015.

${ }^{4}$ NIESR, National Institute of Economic and Social Research, UK, National Institute Global Econometric Model (NiGEM), http://www.niesr.ac.uk/, Accessed October 20, 2015.

${ }^{5}$ URL: www/eviews.com. 


\subsection{Test and Selection of Models}

Except for some special cases, in general, behavioural equations in the Vietnam's model are of the form: $\log (y)=F(y(-k), X, T)$ (abbreviated as $\log (y)=F(y, X, T))$, where $y$ is an endogenous variable, $y(-k)$ is the $y$ variable lagged $k$-steps, $X$ is a set of explanatory variables, $T$ is a time variable, $F$ is the log-linear function of explanatory variables with the trend $T$ (called function of type 1) or is the second order Maclaurin series expansion of the natural logarithm of a dependent variable according to the natural logarithm of explanatory variables with the trend (function of type 2).

In each behavioural equation (or estimated model), explanatory variables selected to input in the equation are based on economic theories and on the available data for these variables. Initially, the selected model is the log-linear function and then testing that whether the conditional expectation of the residual in the estimated model to be equal to 0 . The conditional expectation of the residual other than 0 is one of the main causes of bias OLS estimate. If the conditional expectation of the residual is not zero, it must be tested whether important variables are omitted (using the Wald test [17]). In many cases, the trend variable $T$ must be added to the model as a new explanatory variable. The trend variable $T$ represents all the factors that affect the change of the dependent variable, but have not been reflected in the model. Adding the variable $T$ to the model will increase significantly the value of the $R$-squares. The residual graph is also analysed to find out abnormal points of data. To handle such abnormal data, dummy variables are added to the estimated model. If the conditional expectation of the residual is still non-zero, the test of the wrong format of nominated function will be performed. This paper used the Ramsey test [18] to detect the wrong format of nominated function due to the lack of important variables that are function of the explanatory variables in the model. The functions of the explanatory variables are the second order function (i. e., the square or the cross product of the explanatory variables). When the conditional expectation of the residual to be 0 , we can believe that there is no endogenous problem in the model.

In the context that the data used to build the Vietnam's model were checked and verified carefully then the main reason of the change of the residual variance is due to omitting important variables or the wrong format of nominated function. To check if the residual variance changes or not, I used the While test for Heteroscedasticity [19], whereby the squared residual is tested whether it correlates with explanatory variables, squared ex- planatory variables and the cross product of explanatory variables. From my experience, by basing on the While test, one can be able to identify the right format of nominated function, limit omitting important variables. This can be considered as a way to overcome the phenomenon of changes of the residual variance quite effectively.

The Jacque-Berra test [20] is used to check the distribution of residuals in the estimated models to be normal or not. In the Vietnam's model, there are still certain behavioural equations where the residual is not a normal distribution. However, when the residual is not a normal distribution, statistical inferences are not reliable when the number of samples to be small, but with a large number of samples, such inferences are still valid. In other words, if the distribution of a residual in the estimated model is not normal, it is not a serious violation.

Checking the multicollinearity between the explanatory variables in each behavioural equation is performed by regressing each explanatory variable according to the remaining explanatory variables to obtain all values of the $R$-squares corresponding to all explanatory variables. If there exist a high value of the $R$-squares (it is greater than $0.9)$ then there is a high multicollinearity between the explanatory variables.

In addition, to improve forecast accuracy, all residuals in estimated models are tested for serial correlation using the Breusch-Godfrey test [21, 22]. If there is a serial correlation in the residual, we analyse the autocorrelation and partial correlation functions of this residual to determine the parameters $\mathrm{p}, \mathrm{q}$ in its ARMA model.

In the environment of the EViews software, all the statistical tests aforementioned are done quickly and easily. In the Vietnam's model, all the residuals have the conditional expectation to be 0 ; their variance is constant; there is no high multicollinear relation between the explanatory variables as well as there is no serial correlation in the residuals. So, the behavioural equations in the Vietnam's model have been estimated unbiasedly and are stable.

\section{Structure of the Model}

The Vietnam's model consists of 239 equations including 152 behavioural equations, 87 homogeneous equations, 239 endogenous and 37 exogenous variables. All of the behavioural equations in this model are estimated using the OLS method. The Vietnam's model is organized into the 9 blocks corresponding to the 9 groups of forecasting information for socio - economic development planning. They are: Production \& GDP, 
Population, Employment and Labour demand \& Supply, Income, Consumption, Investment and Capital Stock, State Budget, Inflation and Prices, Foreign Trade and Energy Demand-Supply. The division of the entire model into the 9 blocks, on the one hand, depends on the nature of macro-economic theories and, on the other hand, depends on the initial sources of statistical data and on the functions and tasks of the state management ministries in implementing forecasts for medium-term Socio-economic development planning. The model is summarized according to the blocks as follows:

\subsection{Production and GDP Block}

This block will forecast GDP at constant and current prices of the whole economy, and by the economic sectors of level 1. The GDP is forecasted by both supply and demand approaches with the main purpose to test, to calibrate, and to ensure the consistent of forecasted GDPs as well as to check the conditions to create forecast scenarios. This block consists of 61 equations including 25 behavioural equations and 36 homogeneous equations.

\subsubsection{Forecasting GDP under the demand} approach

GDP at constant prices of the economic sectors is influenced by GDP in the previous period, by foreign demand, by world price of certain input materials and key products of each economic sector, by the changes of economic policies of the government and by the application of advanced technologies and management in every economic sector, etc. Such as GDP of the sector of Agriculture Forestry - Fisheries can be determined by the following equation:

$$
\begin{gathered}
\log (G D P I)= \\
=F(G D P I, W E I, W G D P, P R I C E, W D P A N F, T)(1)
\end{gathered}
$$

here GDPI denotes GDP at constant prices by the sector of Agriculture - Forestry - Fisheries; WGDP, WEI are world GDP and total world trade at constant prices respectively; PRICE, WDPANF are the world price for rice and for the input raw materials for production of the sector of Agriculture Forestry - Fisheries respectively; $\mathrm{T}$ is a time trend variable. In this paper, if without further explanation, GDP at constant prices by the secondary industry as well as by the tertiary industry is defined by the equation:

$$
\log (G D P)=F(G D P, W E I, W G D P, P O I L, T)(2)
$$

here POIL is world price of crude oil. $F()$ is the function of type 1 or function of type 2 . Such as the equation forecasting a GDP at constant prices by the secondary Industry (GDPII) below is a function of type 1 :

$$
\log (G D P I I)=0.479 \log (G D P I I(-1))-
$$

$$
\begin{array}{ccc}
-0.001 P O I L+ & 0.359 \log (W E I)+0.149 \log (\text { WGDP })+ \\
(0.0003) & (0.110) & (0.032) \\
+ & 0.029 T-2.886 \\
& (0.010) \quad(0.097)
\end{array}
$$

$S E: 0.009 ; R^{2}$ : 0.98; DW: 1.1; SMPL: 1996-2015

GDP by the economic sectors of level 1 is determined by the equation (3):

$$
G D P_{x}=F\left(G D P_{x}, G D P Y, T\right)
$$

where $x$ is an economic sector of level 1 belongs to the economic sector $Y$ ( $Y$ is the secondary or tertiary industry). The function $F()$ is the function of type 1.

The exogenous variables in the equations (1), (2) above are forecasted by the Institute of Economic and Social Research - United Kingdom using the global econometric model NiGEM ${ }^{1}$. The formula (3) is modified from [8].

\subsubsection{Forecasting GDP under the supply approach}

GDP by the economic sectors is determined by labour, capital accumulation and total factor productivity (TFP) in this sector with the production technology being the Cobb-Duglas function. Theoretical equations forecasting GDP of the sector $X$ (denoted by $G D P_{x}$ ) by the production approach is given by:

$$
\log \left(G D P_{x}\right)=a \log \left(L D_{x}\right)+b \log \left(K_{x}\right)+c+d T
$$

here: $L D_{x}, G D P_{x}, K_{x}$ are the number of employees, GDP and capital accumulation at constant prices by this economic sector, respectively; $T$ is the time variable. This variable is included in the equation to reflect trends of applying science advances, modern technologies as well as new management methods in the sector. Such as the equations forecasting GDP at constant prices by the secondary industry (or Sector of Industry - Construction) is as follows:

$$
\begin{gathered}
\log (G D P I I)=0.55 \log (K \mathrm{II})+0.45 \log (L D I I)- \\
(0.090) \quad(0.09) \\
-0.028 T+2.95 \\
(0.006) \quad(0.009)
\end{gathered}
$$

SE: 0.032; $R^{2}: 0.995 ; D W: 1.20 ;$ SMPL: 1996-2015; here $L D I I, K I I$ are the labour, capital accumulation in the secondary industry respectively. The nega-

\footnotetext{
${ }^{1}$ NIESR, National Institute of Economic and Social Research, UK, National Institute Global Econometric Model (NiGEM), http://www.niesr.ac.uk/, Accessed October 20, 2015.
} 
tive coefficient of $T$ implies that the efficiency of applications of new management approaches and modern technologies in this industry tends to decrease and in fact, the ICOR of this industry has tended to increase over the years.

To forecast GDP under the supply approach in the period 2016-2020, first of all, I must forecast values of exogenous variables in the equation (4) in this period. These are the number of employees who are participating in economic activities $(L D)$ and capital accumulation $(K)$ in the whole economy as well as in each economic sector. These forecasted values are taken from the Block concerning Population, Employment and Labour, and the Block about Investment below.

\subsection{Population, Employment and Labour demand \& Supply Block}

This block will forecast the national average population, the urban population and the rural population; forecast the labour demand by 9 standard occupations and by training levels in the whole economy and in the 21 economic sectors of level 1. This block consists of 51 equations including 41 behavioural equations and 10 homogeneous equations. Theoretical equation to forecast the national average population is an autoregressive model of order $\mathrm{p}$ with the trend:

$$
\log (P O P)=F(P O P, T)
$$

here $P O P$ is the annual average population. The specific equation forecasting the annual average population is as follows:

$$
\begin{gathered}
\log (P O P)=0.878 \log (P O P(-1))+2.230+ \\
(0.04) \quad 0.75) \\
+0.001 T-0.555 A R(2)+0.99 M A(1) \\
(0.0004) \quad(0.19) \quad(0.18)
\end{gathered}
$$

$S E:$ 9.99.e-08; $R^{2}: 0.98 ; D W: 1.48$;

SMPL: 1999-2015;

Theoretical equation to forecast the urban population is defined by:

$$
\log (P O P U R)=F(P O P U R, P O P, T)
$$

here POPUR is the urban population; $F()$ is a function of type 1 mentioned above.

Labour demand in each economic sector of level 1 is forecasted by the equation (7) below:

$$
\log \left(L D_{x}\right)=F\left(L D_{x}, G D P_{x}, T\right),
$$

here $G D P_{x}, L D_{x}$ are GDP at constant prices and the number of employees participating economic activities in the economic sector $\mathrm{x}$ respectively; $F()$ is the function of type 1 . The equation (7) says that the labour demand in an economic sector depends on the number of labours in the sector in the past, on the economic growth of this sector, and on many other factors, most notably the application of new management methods and modern technologies. For example, the specific equation to forecast labour demand in the secondary industry is as follows:

$$
\begin{gathered}
\log (L D \mathrm{II})=0.84 \log (L D \mathrm{II}(-1))+ \\
(0.10) \\
+0.19 \log (G D P \mathrm{II})-0.008 \mathrm{~T} \\
(0.09) \quad(0.001)
\end{gathered}
$$

$S E: 0.002 ; R^{2}$ : 0.98; DW: 1.97; SMPL: 1999-2015;

here, the negative coefficient of $T$ implies that the other factors have contributed to reduce demand for labour in the secondary industry.

Forecasting the labour demand by standard occupations or training levels for the whole economy is implemented via forecasting odd ratios. Theoretical equations to forecast odd ratios are defined as below:

$$
\log (O D D S)=F(O D D S, T)
$$

here $O D D S=\frac{p}{1-p}, p$ is the employment rate for the occupation $S$ or for the training level $S$ in the total of employments; $F()$ is the autoregressive model of the order $q$ with the trend. Namely, the equation forecasting the odd ratio of employment with the training levels from the university or higher degree in the whole economy is as follows:

$$
\begin{aligned}
\log (O D D 5)= & -3.78+0.085 T-0.179 D_{2008} ; \\
& (0.03)(0.003) \quad(0.07)
\end{aligned}
$$

$S E: 0.072 ; R^{2}$ : 0.972; DW: 2.08; SMPL:1999-2015; $D_{2008}$ is a dummy variable for 2008 .

The dummy variable $D_{2008}$ is used, because in 2008 , the employees with university education or higher had a sudden decline in the economy. In fact, in that year, the Vietnam's economy was strongly affected by the global financial crisis and economic recession, and university graduates were hard to find a suitable job for their training field and level. Many skilled labourers in many industrial parks and export processing zones left their jobs to for manual works in the tertiary industry or moved to work in the primary industry (or the sector of agriculture, forestry and fishery).

To forecast labour demand by the 9 standard occupations of level 1 and the 5 training levels in the 21 economic sectors of level 1, the RAS method was used [11, 23-24].

\subsection{Income Block}

This block forecasts the income of urban and rural populations. The income figures are synthesized and processed from the surveys about stand- 
ards of living of residents and households. This block consists of 3 equations including 2 behavioural equations 2 and 1 homogeneous equation. The income of people depends on their income in the previous periods and depends on the growth of production or GDP. The income of rural population depends mainly on GDP by the primary industry, while the income of urban residents depends mainly on GDP by the secondary and tertiary industries [8]. In addition, the income of people depends on social policies of the Government. To be able to grasp it, the time variable $\mathrm{T}$ is included in the model as an explanatory variable. In other words, theoretical equations to forecast the income of urban and rural populations are defined respectively as follows:

$$
\begin{gathered}
\log (\text { INCRU })=F(I N C R U, G D P I, T) \\
\log (I N C U R)=F(I N C U R, G D P I I+G D P I I I, T)
\end{gathered}
$$

here INCRU, INCUR are income at constant prices of rural and urban population respectively; GDPI, GDPII, GDPIII are GDP at constant prices by the primary, secondary and tertiary industries, respectively. $F()$ is the function of type 1 .

The equation to forecast income of urban population namely is as below:

$$
\begin{gathered}
\log (\text { INCUR })=1.84 \log (G D P I I+G D P I I I)- \\
(0.0004) \\
-0.045 T-0.06 D_{2008} . \\
(0.0007) \quad(0.011)
\end{gathered}
$$

$S E: 0.011 ; R^{2}$ : 0.999; DW: 2.22; SMPL: 1999-2015;

With the global financial crisis and economic recession in the period 2007-2010, from the end of 2007 to 2012, the inflation rate of the Vietnam's economy was very high (average is nearly $20 \%$ ), this rate was gradually decreased and returned to normal status in the end of 2015, while the growth rate of the period 2010-2015 was quite low. The result of the Vietnam's Living Standard Surveys shows that the global financial crisis and economic recession had the strongest impacts on the income of urban population. It is the main reason to explain why the real income of urban population tends to decrease over the years. The negative coefficient of $\mathrm{T}$ in the estimated equation for the income of the urban population demonstrates it. Moreover, the real income of urban population in Vietnam in 2008 fell very deeply and suddenly, so the dummy variable $D_{2008}$ is also used in this estimated equation.

\subsection{Consumption Block}

This block forecasts household consumption and public consumption. The block consists of 3 equations including 2 behavioural equations and 1 homogeneous equation. The behaviour of household consumption is affected by consumption habits, and the consumption level depends on income and on consumption in the previous periods. Therefore, the income should be explanatory variable in the forecasting equation concerning consumption [8]. However, for Vietnam, the process of opening up and integrating to the world has changed the consumption behaviour of people, so theoretical equation to forecast consumption of household at constant prices (CONSPRI) is defined as follows:

$$
\log (C O N S P R I)=F(C O N S P R I, I N C R U+I N C U R, T)(11)
$$

here $F()$ is the function of type 1 .

Public consumption depends on the level of consumption in the previous periods and public investment (or government investment), especially investment for national security and defence, for ensuring social security in order to deal with the instability of the region. Hence theoretical equation to forecast public consumption at constant prices (CONSGOV) is defined as below:

$$
\log (\mathrm{CONSGOV})=F(\mathrm{CONSGOV}, I G, T)(12)
$$

here $I G$ is the public investment at constant prices; $F()$ is the function type 1 . The forecast equation namely is:

$$
\begin{gathered}
\log (\text { CONSGOV })=\underset{(0.129)}{0.582} \log (\text { CONSGOV }(-1))+ \\
+0.099 \log (I G(-1))+3.44+0.023 T
\end{gathered}
$$

$S E:(0.0090) ; R^{2}: 0.9994 ; D W: 1.84$; SMPL: 1999-2015.

\subsection{Investment and Capital Stock Block}

This block will forecast total investment for development of the whole society, total accumulation of fixed assets and of current assets in the whole economy and capital accumulations in the 3 primary, secondary and tertiary industries. This block consists of 17 equations including 7 behavioural equations and 10 homogeneous equations.

Total investment for the development of the whole society is the total investment in the three economic sectors of state, private and foreign investment. Namely, $I N=I S+I P+I F S$, where $I N, I S$, $I P, I F S$ are total investment for the development of the whole society and investment in the state, private and foreign-invested sectors, respectively at constant prices.

The investment by the state sector includes government investment (from the state budget and from the credits of government) and investment from the capital of state-owned enter- 
prises (SOEs). The characteristics of this capital in Vietnam are heavily dependent on government policies, because, on the one hand, the Government retains the right to decide on investment projects based on the state budget and the credits of government, and, on the other hand, the Government also has the right to intervene strongly to large investment projects of SOEs. Hence, the government investment $(I G)$ is considered as exogenous variables in the model. Theoretical equation to forecast investment in the state sector is of the form:

$$
\log (I S)=F(I S, I G, G D P)
$$

here $F()$ is the function of type 1 . The specific equation is as follows:

$$
\begin{gathered}
\log (I S)=-0.64 \log (I S(-1))+1.072 \log (G D P)+ \\
(0.390) \quad(0.280) \\
+0.422 \log (I G(-1)) \\
(0.189) \\
S E:(0.051) ; R^{2}: 0.893 ; D W: 1.61 \\
\text { SMPL: } 2005-2015 ;
\end{gathered}
$$

In the private sector, the investment depends mainly on the production (GDP at constant prices), long-term lending rates (IRLD), ratio of credits for the private sector $(P C)$ in GDP at current prices $(G D P V)$ and expectations regarding the situation of Vietnam's economic development in the future as well as geopolitical instability in the region. So theoretical equation to forecast investment by the private sector is defined as below:

$$
\log (I P)=F(G D P, I R L D, P C / G D P V)
$$

here $F()$ is the function of type 1, namely:

$$
\begin{aligned}
& \log (I P)=0.291 \log (P C / G D P V)+ \\
& (0.023) \\
& +0.572 \log (G D P)-0.245 \log (I R L D) \\
& (0.051) \quad(0.156)
\end{aligned}
$$

$S E: 0.044 ; R^{2}: 0.975 ; D W: 2.02 ; S M P L: 2005-2015$;

In the foreign-invested sector, in the medium and long term, the investment depends on inside and outside factors of the country, and is expressed most clearly through the foreign direct investment $(F D I)$. For a low wage economy, $F D I$ is indeed an important tool for economic development. It has also become an increasingly important tool to reduce social inequalities and to improve the productivity of domestic firms [25-26].

The FDI depends on many factors such as the size and growth potential of the economy (expressed through GDP); Profitability - is seen as the engine and the ultimate goal of foreign investors; Cost: reducing costs is an issue that foreign investors are interested in, in particular the cost of labour. The labour cost is considered as one of the most important factors when foreign investors make investment decisions. In addition, there are several other expenses that were also considered such as transportation costs, costs of land use, policies about investment incentives or tax for export and import, etc. The FDI depends also on competitive advantages including resources (human resources, natural resources and geographic location), and on the conditions of infrastructure and other political factors. FDI depends also heavily on implementation of commitments in the bilateral and multilateral relations, and investment policy of the government. But the reality of current statistic work in Vietnam shows that quantifying the all factors above is impossible, so the model considered FDI as an exogenous variable. And the investment of the foreign - invested sector (IFS) is determined through FDI. Theoretical equation to forecast IFS is defined as follows:

$$
\log (\text { IFS })=F(I F S, F D I)
$$

here $F()$ is the function of type 1 . The forecast equation namely is:

$$
\begin{gathered}
\log (I F S)=0.95 \log (I F S(-1))-0.94 \log (F D I(-1))+ \\
(0.119) \quad(0.116) \\
+1.001 \log (F D I) \\
(0.106) \\
S E:(0.059) ; R^{2}: 0.965 ; D W: 1.68 ; \\
\text { SMPL: } 2005-2015 ;
\end{gathered}
$$

The total accumulation of assets (ACA) and the total accumulation of fixed assets (ACF) at constant prices depend on themselves and total investment at constant prices in the previous periods and in the current time (show continuity of economic activity as well as demand of the projects during implementation of the SEDPs) as well as depend on changes of relationship between the asset accumulation and the investment. Theoretical equations to forecast ACA and ACF are defined respectively as below:

$$
\begin{aligned}
& \log (A C A)=F(A C A, I N, T) \\
& \log (A C F)=F(A C F, I N, T)
\end{aligned}
$$

Such as the equation forecasting the accumulation of fixed assets (ACF) specifically as follows:

$$
\begin{gathered}
\log (A C F)=0.089 \log (A C F(-2))+0.92 \log (I N)- \\
(0.053) \quad(0.052) \\
-0.017 T+0.66 A R(1) ; \\
(0.003) \quad(0.173) \\
S E:(0.016) ; R^{2}: 0.9988 ; D W: 1.62 ; \\
S M P L: 1996-2015 ;
\end{gathered}
$$

where the negative coefficient of $T$ in the equation also shows that the investment efficiency of the economy tends to decrease. 
The investments in the primary, secondary and tertiary industries are determined in the same manner, namely they depend on the investment in the industry in the previous periods and the total investment for development of the whole society.

$$
\log \left(I N_{x}\right)=F\left(I N_{x}, I N, T\right),
$$

here $I N_{x}$ is the investment at constant prices in the industry $x(x=i, i i, i i i)$, here $i, i i, i i i$ are symbols for the primary, secondary and tertiary industries, respectively. Namely, the equation to forecast investment in the secondary industry is:

$$
\begin{gathered}
\log \left(I N_{i i}\right)=-\begin{array}{l}
0.442 \log \left(I N_{i i}(-1)\right)- \\
(0.134)
\end{array} \\
-0.426 \log \left(I N_{i i}(-2)\right)-0.326 \log \left(I N_{i i}(-3)\right)+ \\
(0.118) \quad(0.107) \\
+1.67 \log (I N)+1.222 \log \left(G D P_{i i}\right)-11.512 \\
(0.185) \quad(0.241) \quad(0.167) \\
\text { SE: }(0.038) ; R^{2}: 0.9967 ; D W: 1.49 ; \\
\text { SMPL: } 1995-2015 .
\end{gathered}
$$

The accumulation of capital (or capital stock: $\mathrm{K})$ at constant prices of the whole economy as well as of the primary, secondary and tertiary industries is defined by the formula:

$$
K=K(-1)(1-d r)+A C F
$$

here $d r$ is the depreciation rate of the whole economy or of each sector in the three sectors above.

\subsection{State Budget Block}

This block forecasts the budget revenue and expenditure according to the inflows of revenue and expenditure according to the state budget law. The block consists of 31 equations while 24 behavioural equations and 7 homogeneous equations.

Total of budget revenue equals sum of all revenues at current prices according to the revenue inflows specified in the state budget law. Forecast method of budget revenue according to each inflow is defined based on its revenue in the previous years at current prices, growth of GDP and taking into account budget revenue policies changed by the Government. In other words, theoretical equation to forecast the budget revenue by the revenue Inflow named $x$ is of the form:

$$
\log \left(R E V_{x} / G D P D e f\right)=F(R E V x / G D P d e f, G D P, T)
$$

here $R E V_{x}$ is the budget revenue at current prices of the revenue inflow named $x$, GDPDef is the GDP deflator; $F()$ is the function of type 1 or type 2 depends on each specific revenue inflow. Such as the equation of forecasting the revenue from taxes $(T A X)$ is namely as follows:

$$
\log (\text { REVtax } / \text { GDPDef })=5.50 \log (G D P(-1))-
$$

$$
\begin{gathered}
-64.37-0.29 T ; \\
\text { (9.80) } \quad(0.04)
\end{gathered}
$$

SE: (0.038); $R^{2}$ : 0.989; DW: 1.99; SMPL: 2001-2015.

The specific equation above shows that in Vietnam, TAX revenue is dependent strongly on GDP at constant prices in the last year and this dependency tends to decrease over time (due to the coefficient of $\mathrm{T}$ is negative). This is suitable. Vietnam is in the process of cutting and reducing tariffs, especially export and import taxes when implementing bilateral and multilateral agreements, for example, implementing the schedule for cutting and reducing taxes of ASEAN Economic Community (AEC), etc.

The budget expenditure (or government expenditure) is defined according to the expenditure lines detailed in the state budget law. In these lines, the expenditures on health, education, poverty reduction, national security and defence are exogenous variables because they depend strongly on the policies of the Government. Other expenditure lines can be determined by behaviours equations in which the expenditure in the previous periods, total of budget revenue are factors effecting future expenditures. Theoretical equation to forecast the budget expenditure for the expenditure line named $\mathrm{x}$ is defined by:

$$
\begin{gathered}
\log \left(E X P_{x} / G D P D e f\right)= \\
=F\left(E X P_{x} / G D P D e f, R E V / G D P D e f, T\right)
\end{gathered}
$$

here $E X P_{x}, R E V$ are the budget expenditure line named $X$ and total of budget revenue at current prices respectively; $F()$ is the function of type 1 or type 2 depending on each specific expenditure line.

\subsection{Inflation and Prices Block}

This block forecasts the Consumer Price Index $(C P I)$, Investment Price Index for development (PIN), GDP deflator of the whole economy (GDPdef) and of the 21 economic sectors of level 1 $\left(G D P d e f_{x}\right)$, Export Price Index of merchandises and services (PEX), Import Price Index of merchandises and services (PIM), in which the CPI and PIN indexes are considered as two basic price indexes in this block [8]. All other price indexes are determined through these two price indexes.

This block provides data to switch between the constant prices and the current prices for many other macro-economic indicators. The block consists of 32 equations including 27 behavioural equations and 5 homogeneous equations. Theoretical equation to forecast CPI is defined as follows:

$$
\begin{gathered}
\log (C P I)= \\
=F\left(C P I, M_{2} / G D P V, I N / G D P, P R I C E,\right. \\
\text { POIL, WDPANF }, T)
\end{gathered}
$$


here $M_{2}, G D P V$ are total means of payments and GDP at current prices, respectively. The variable $I N / G D P$ shows level of investment, it reflects the cause of inflation by demand-pull; PRICE, POIL and WDPANF are the world prices of rice, crude oil and raw materials for production of agriculture, forestry and fishery, respectively and they reflect the cause of inflation by cost-push; $M_{2} /$ $G D P V$ express national monetary policy reflecting the cause of inflation by monetary; lagged GDP reflects the inflation caused by expectations. The variable $\mathrm{T}$ reflects other hidden reasons which are not expressed in the explanatory variables as mentioned above and it changes over time. The specific equation to forecast CPI is of the form:

$$
\begin{gathered}
\log (C P I)=0.73 \log (C P I(-1))+0.19 \log (C P I(-2))- \\
(0.083) \quad(0.074) \\
-0.25 \log (I N / G D P)+0.28 \log (I N(-1) / G D P(-1))+ \\
(0.072) \quad(0.093) \\
+0.24 \log (P R I C E)-0.26 \log (P R I C E(-1))+ \\
(0.028) \quad(0.020) \\
+0.05 \log \left(M_{2} / G D P V\right)+0.10 \log (\text { WDPANF })+ \\
(0.035) \quad(0.044) \\
+0.066 \log (P O I L) \\
(0.017) \quad 0.975 ; D W: 2.87 ; \\
\text { SMPL: } 1995-2015 ;
\end{gathered}
$$

Theoretical equation to forecast PIN is defined as folows:

$$
\log (P I N)=F\left(P I N, M_{2} / G D P V, I N / G D P, P O I L, T\right)
$$

The role of the explanatory variables as PIN, $M_{2} / G D P V, I N / G D P$ in the equation (23) is interpreted similarly as in the equation (22) above. The variable POIL in equation (23) implies that the energy in general is a significant cost to implement investment projects. The equation to forecast PIN namely is of the form:

$$
\begin{gathered}
\log (P I N)=-0.53 \log (I N / G D P)+ \\
(0.13) \quad(0.23)(0.004) \\
+0.67 \log (I N(-1) / G D P(-1))+4.70-0.014 T+ \\
(0.12) \quad(0.027) \\
+0.074 \log \left(M_{2}(-1) / G D P V(-1)\right)+0.39 A R(1) ; \\
(0.04) \quad(0.032) ; R^{2}: 0.703 ; D W: 2.04 ; \\
\text { SMPL: } 1995-2015 ;
\end{gathered}
$$

This equation indicates that the PIN depends strongly on the ratio $I N / G D P$ of the previous year (in the same direction) as well as of the current year (in the opposite direction), depends only on the $M_{2} / G D P V$ ratio of the last year (in the same direction) but not strongly. The coefficient of $T$ is negative indicating that the PIN tends to decrease. This is a practical fit. In order to response to high inflation in Vietnam in 2008-2012, the Government has implemented many policies to limit new public investment projects, eliminate ineffective public investment projects, promote implement of effective investment projects. Moreover, the Government has promulgated and implemented the medium-term and long-term public investment Law (from 2013).

Theoretical equations to forecast the GDP deflator (GDPdef) of the whole economy as well as of the 21 economic sectors of level 1, and the PEX and PIM indexes of the economy are defined as below:

$$
\log (Y)=F(Y, C P I, P I N, T)
$$

here $Y$ is one of the 3 specified type of price indexes mentioned above; $F()$ is the function of type 1 or type 2 .

\subsection{Foreign Trade Block}

This block forecasts total exports and imports at constant prices and current prices. This block consists of 33 equations including 24 behavioural equations and 9 homogeneous equations. Theoretical equation to forecast total exports at constant prices is defined by:

$$
\log (E X)=F(E X G, E R, P E X / P C E X, T)
$$

here $E R$ is the exchange rate between $V N D$ and $U S D, P E X$ is the Export Price Index of Vietnamese merchandises and services; PCEX the Export Price Index of Chinese merchandises and services (collected from NIGEM) and the ratio of PEX/PCEX reflects the competitiveness about the export prices of merchandises and services of Vietnam and World, EXG is growth rate of export markets for Vietnam's merchandises and services. EXG is determined by the formula:

$$
E X G=\sum x_{k} I M G_{k}
$$

$x_{k}$ is the import ratio of the $k$-th country for Vietnam's export merchandises and services in comparing with Vietnam's total export; $I M G_{k}$ is the import growth of the $k$-th country for Vietnam's export merchandises and services. We've selected 17 countries, which are the leading import countries, and the rest of the countries are grouped to put into the econometric model. The import growth rate of world and of the 17 selected partners was forecasted by IMF. In order to forecast $E X G$, the remaining problem is to forecast the import ratios of the 17 selected countries and of the remaining group of countries for Vietnam's export merchandises and services (i. e. forecasting $x_{k}$ ). 
The method of forecasting these ratios is similar as the forecast method presented in the equation (8) above. The specific equation to forecast total exports $(E X)$ is the function of type 2 as follows:

$$
\begin{gathered}
\log (E X)=0.42 \log (E X G)-0.35 \log (P E X / P C E X)+ \\
\quad(0.092) \quad(0.094) \\
+2.55 \log (E R)-0.15 \log (E R)^{\wedge} 2+0.012 T \\
\quad(0.131) \quad(0.012)
\end{gathered}
$$$$
S E:(0.021) ; R^{2}: 0.9990 ; D W: 1.35 \text {; }
$$

SMPL: 1997-2015.

Theoretical equation to forecast total imports at constant prices is the modified import demand function and is defined by:

$$
\log (I M)=F(C O N S R U+C O N S U R, I N, E X, T)
$$

here $I M$ is total imports at constant prices, and the equation to forecast total imports namely is:

$$
\begin{aligned}
& \log (I M)=0.79 \log (E X)+0.015 \log (I N)^{\wedge} 2+ \\
& \text { (0.183) (0.003) } \\
& +1.27 \log (\mathrm{CONSRU}+\mathrm{CONSUR})-16.70- \\
& \text { (0.490) } \\
& -0.09 T+0.34 A R(1) \\
& (0.034) \quad(0.023)
\end{aligned}
$$

$S E:(0.019) ; R^{2}: 0.9992 ; D W: 2.08$; SMPL: 1997-2015.

The coefficient of $T$ in the above equation is negative indicating that the growth rate of Vietnam's import is tending to decrease compared to exports. This is in line with reality. In the 20082011 period, the trade deficit of Vietnam is very high (specially the deficit of merchandise trade), then gradually reduced and even from 2015, Vietnam had the surplus of merchandise trade.

\subsection{Energy Demand and Supply Block}

This block focuses first on forecasting the energy demand. It consists of 8 equations including 5 behavioural equations and 3 homogenous equations. Theoretical equation to forecast the energy consumption in primary and secondary industries is defined as below:

$$
\log (Y E)=F\left(Y E, G D P_{x}, P R E_{1}, T\right)
$$

here $G D P_{x}$ is GDP at constant prices by primary industry or secondary industry; $Y E$ is the consumed energy by each industry; and $P R E_{1}$ is the eleecrticity price for production at constant prices; $T$ is the time variable. Such as the specific equation to forecast energy demand of the secondary industry (denoted by $I D E$ ) is as follows:

$$
\log (I D E)=-\underset{(67.58)}{-292.50} \log (G D P I I)+1291.51+
$$

$$
\begin{gathered}
+0.39 \log (I D E(-1))+22.08 \log (G D P I I)^{\wedge} 2- \\
(0.15) \quad(0.11) \\
+0.55 \log (G D P I I)^{\wedge} 3 \\
(0.013)
\end{gathered}
$$

SE: (0.02); $R^{2}:$ (0.9992); DW: 1.85; SMPL: 1995-2015.

Theoretical equation to forecast the consumed electricity in the tertiary industry $(S V E)$ is defined by:

$$
\log (S V E)=F\left(S V E, G D P I I I, P R E_{2}, T\right)
$$

here $S V E$ is the consumed electricity in the tertiary industry; GDPIII and $P R E_{2}$ are GDP of this industry and the energy price for business at constant prices, respectively.

Theoretical equation to forecast the consumed electricity for civil purposes $(C I E)$ is defined as below:

$$
\begin{gathered}
\log (\text { CIE })=F(C I E,(\text { INCRU } / \text { RUHOUS })+ \\
\left.+(\text { INCUR }) / U R H O U S), \text { PRE }_{3}, T\right)
\end{gathered}
$$

here CIE is the consumed electricity for the purpose of civil use; $P R E_{3}$ is the electricity price at constant prices for the civil use; URHOUS, RUHOUS are the number of households in urban and in rural area, respectively.

Theoretical equation to forecast the consumed electricity for other use purposes (OTE):

$$
\log (O T E)=F(O T E, G D P V / P O P, P R E, T)
$$

here $P R E$ is the aggregation electricity price calculated on the basis of the weighted average of the electricity prices for production, for business and for civil use (Mark, 2011). Such as the equation of forecasting the consumed electricity for other use purposes namely is:

$$
\begin{aligned}
\log (O T E)= & 3.12 \log (G D P V / P O P)+28.40+ \\
& (1.50) \\
& +0.09 T-0.21 d_{2007} ; \\
& (0.03) \quad(0.09)
\end{aligned}
$$

$S E:(0.09) ; R^{2}: 0.989 ; D W: 1.61 ; S M P L$ 1995-2015.

The coefficient of $T$ in the above equation is positive indicating that the energy demand for other use purposes (entertainment, sports, culture, lighting, etc.) is increasing. It reflects the living standards of the Vietnamese people are being improved.

In 2007, Vietnam officially joined the WTO, the foreign direct as well as indirect investment increased very highly. People expected so much on prospects of the economy. They expanded boldly their investments, promoted consumption as well as increased participation in the activities of entertainment, culture, tourism, sports etc. That leaded to high demand for energy, especially elec- 
tricity demand in the service industries, for the purpose of civil and other uses. And the dummy variable $\mathrm{d} 2007$ is used to overcome this situation.

\section{Conclusions}

This paper showed that the main ideas of the forecasting procedures for 5 -year and annual socio-economic development planning in Vietnam are quite similar to the forecasting procedures for strategic planning in the Russian Federation, although the forecasting procedures in Vietnam are not comprehensive, lacking in detail and not consistent. There are some limitations of implementing the procedures in the development planning in Vietnam. Further, the current state of old forecasting models for the five-year and annual socio-economic development planning showed the urgent need of developing a macro econometric model for the socio-economic development planning in Vietnam.

The paper introduced the theoretical framework of the Vietnam's model. The methodology of testing and selecting the right format of function nominated for behavioural equations in this model was also introduced in detail. From that it can believe that the unbiasedness and stability of the OLS estimate are ensured.

This paper presented very briefly the structure of the macro-econometric model supporting the implementation of forecasting procedures for annual and 5 years socio-economic development planning in Vietnam. These procedures are being elaborated in detail in a manner that is quite similar to the forecasting procedures for strategic planning in the Russian Federation. The mutual relationships of the indicators forecasted by the built model were developed from the main ideas of the system of forecast models for strategic planning in the Russian Federation.

The main applications of the Vietnam's model will be detailed in the future research.

The modelling approach in this paper can be applied to those countries that are in the process of building the market economy having the deep integration with the world economy and still maintain socio-economic development plans as important tools for managing and regulating the economy. This approach can also be applied to build forecasting models for socio-economic development planning at the provincial scope in Vietnam.

\section{Acknowledgements}

I would like to thank Dr. Strizhkova L. A., Assoc. Prof. Kuranov G. O., PhD. Kuranov A. G., Dr. Mukhina I. I., Dr. Kuznetsov S. G., PhD. Goncharenko A. N., Dr. Kirichenko I. A., PhD. Smirnov A. V., PhD Slobodyanik, S.N. and other researchers from the Institute for Macroeconomic Research, Ministry of Economic Development of the Russian Federation who shared their experiences about the forecasting procedures and methodologies for strategic planning in the Russian Federation. I would like to thank Dr. Kirichenko I. A., PhD. Smirnov A. V., Prof. Minh N. K., Assoc. Prof. Tuan B. Q., PhD. Duc L. V. had have many valuable comments for this model; to thank masters: Hao D.T., Ngoc B. B., Lam D. V., Huong L. T., Nhuong C. T., Anh L. Q., Hien N. M., Minh T. H., Linh N. H. and Dung N. V. from the National Center for Socio-Economic Information and Forecast, Ministry of Planning and Investment of Vietnam who supported me in preparing data to build the model. This research has been carried out in the framework of the project "Research on medium-term socio-economic forecasting methodologies in the Russian Federation and its applicability to Vietnam" and was funded by Vietnam's Ministry of Science and Technology, Contract No. 18/2014/HĐ-NĐT.

\section{References}

1. Thanh D. V. (2017). Báo cáo tổng hợp: Nghiên cứu phương pháp dư báo kinh tế - xã hội trung hạn ở Liên bang Nga và khả năng û́ng dụng vào Việt Nam [Synthesis Report: Research on medium-term socio-economic forecasting methodologies in the Russian Federation and its applicability to Vietnam]. Vietnam: National Library of Science and Technology, 359. (in Vietnamese).

2. Kirichenko, I. A. and Smirnov, A. V. (2015). Forecasting procedures for strategic planning in the Russian Federation, Workshop: Forecasting methodology for medium-term Socio-economic development planning in the Russian Federation and its applicability to Vietnam. Jun 25, 2015, Hanoi.

3. Strizhkova, L. A. (2012). K Voprosu Ucheta Sistemnykh Sviazei pri Sostavlenii Makroekonomicheskogo Prognoza [The role of system relations, in macroeconomic forecasts]. Sbornik Nauchnykh Trudov IMEI [Proceedings of the Institute of Macroeconomic Research], 2, 26-78. (in Russ)

4. Yekimova, K.V., Savelyeva, I. P. \& Tsalo I. M. (2016). Otsenka Vliianiia Izmenenii Koniunktury Mirovykh Rynkov na Regional'nye Protsessy [Assessment of the Impact of the Changes in the Situation of the World Markets on the Regional Processes]. Economy of Region, 12(3), 670-683. doi: 10.17059/2016-3-5. (in Russ)

5. Kirichenko I. A. \& Smirnov A. V. (2013). Vliianie makroekonomicheskikh pokazatelei na formirovanie investitsionnykh protsessov v ekonomike [Influence of Macroeconomic Indicators on the development of investment processes in the economy], Sbornik Nauchnykh Trudov IMEI [Proceedings of the Institute of Macroeconomic Research], 2, 7- 59. (in Russ)

6. Kuranov A.G.(2012). Analiz Ustoichivosti Reshenii Modeli Mezhotraslevogo Balansa [Analysis of solution stability in IO models]. Sbornik Nauchnykh Trudov IMEI [Proceedings of the Institute of Macroeconomic Research], 2, 79-94. (in Russ) 
7. Slobodyanik, S. N. (2013). Metodologicheskie Podkhody k Formirovaniiu Informatsionnoi Bazy dlia Otsenki Protsessov Energoberezheniia v Rossiiskoi Ekonomike [Methodological Approaches to Information Database Organization for Assessing Energy-saving Processes in the Russian Economy]. Nauchnye Trudy: Institut Narodnokhoziaistvennogo Prognozirovaniia RAN [Scientific Articles — Institute of Economic Forecasting Russian Academy of Sciences], 11, 430-454. (in Russ)

8. Shen, L. (2000). China's Macro Econometric Annual Model. In: Klein, L. R. and Ichimura S. (eds.). Econometric Modeling of China, chapter 7 (pp. 307-320). World Scientific Publishing Co. Pte. Ltd.

9. Yoshihisa, I. (2000). ICSEAD's Econometric Model of the Chinese Economy. In: Klein, L. R. and Ichimura S. (eds.). Econometric Modeling of China Econometric Modeling of China, chapter 2 (pp.68-150). World Scientific Publishing Co. Pte. Ltd.

10. Youcai, L. (2000). China's economic model for project FAIR. In: Klein, L. R. and Ichimura S. (eds.). Econometric Modeling of China Econometric Modeling of China, chapter 4 (pp. 201-245). World Scientific Publishing Co. Pte. Ltd.

11. Insoo J. \& Thanh D.V. (2013). Forecasting Labour demand (2011-2020) and Setting up Employment Information Services in Vietnam, Working paper, the Program to share knowledge of Korea to Vietnam, 1-64.

12. Mark, D. (2011). Review of MED's demand forecasting methodology, Ministry of Economic Development (MED), New Zealand, 11, 1-53. [Electronic resource] Available at: https://www.mbie.govt.nz/building-and-energy/ (Date of access: 25.09.2018).

13. Armstrong J. S. \& Kesten C. G. (2018). Forecasting methods and principles: Evidence-based checklists. Journal of Global Scholars of Marketing Science, 28(2), 103-159. doi: 10.1080/21639159.2018.1441735.

14. Armstrong, J. S. and Collopy, F. (1998). Integration of Statistical Methods and Judgment for Time Series Forecasting: Principles from Empirical Research. Forecasting with Judgment, 269-293 [Electronic resource]. Available at SSRN: https:// ssrn.com/abstract $=648736$ (Date of access: 25.09 .2018 ).

15. Lim, J. S., \& O'Connor, M. (1995). Judgemental adjustment of initial forecasts: Its effectiveness and biases. Journal of Behavioral Decision Making, 8, 149-168. doi:10.1002/bdm.3960080302.

16. Komkov, N. I., Selin, V. S., Tsukerman, V. A., \& Goryachevskaya, E. S. (2016). Scenario Forecast of the Development of the Northern Sea Route. Studies on Russian Economic Development, 27 (2), 180-188. doi: 10.1134/S1075700716020076.

17. Engle, R. F. (1984). Wald, Likelihood Ratio, and Lagrange Multiplier Tests in Econometrics. In: Griliches, Z. \& Intriligator, M. D. (eds.). Handbook of Econometrics. Vol. 2. North Holand, Amsterdam, pp. 775-826.

18. Ramsey, J. B. (1969). Tests for Specification Errors in Classical Linear Least-Squares Analysis, Journal of the Royal Statistical Association, Series B: Methodological, 31, 350-371.

19. While, H. (1980). A Heteroskedasticity - Consistent Covariance Matrix Estimator and a Direct Test Heteroskedast icity. Econometrica, 48( 4), 817-838.

20. Jacque C. M. \& Bera, A. K. (1987). A test for normality of observations and regression residuals. International Statistical Review, 55(2), 163-172.

21. Breusch, T. S, (1978). Testing for Autocorrelation in Dynamic Linear Models. Australian Economic Papers, 17, 334-355.

22. Godfrey, L.G, (1978). Testing Against General Autoregressive and Moving Average Error Models when the Regressors Include Lagged Dependent Variables. Econometrica, 46, 1293-1302.

23. Van Eijs, P. \& Borghans, L. (1996). The use of RAS in manpower forecasting: A microeconomic aprroach. Economic Modelling, 13, 257-287.

24. Sinkhorn, R.D. \& Knopp P. J. (1967). Concerning nonnegative matrices and doubly stochastic matrices. Paccific Journal of Mathematics, 21(2), 1967, 343-349.

25. McLaren, J. \& Yoo, M. (2017). FDI and Inequality in Vietnam: An approach with census data. Journal of Asian Economics, 48, 134-147. doi:10.1016/j.asieco.2016.11.002.

26. Ni, B., Spatareanu, M., Manole, V., Otsuki, T. \& Yamada, H. (2017). The origin of FDI and domestic firms' productivity-Evidence from Vietnam. Journal of Asian Economics, 52, 56-76. doi: 10.1016/j.asieco.2017.08.004.

\section{Author}

Do Van Thanh - Associate Professor, Nguyen Tat Thanh University (300A Nguyen Tat Thanh Str., Ward 13, District 4, 72820, Ho Chi Minh, Vietnam; e-mail: dvthanh@ntt.edu.vn). 